\title{
Aumento da Eficácia do Aprendizado de Soldagem por Aulas Práticas Assistidas por Audiovisual de Forma Não Passiva
}

\author{
Américo Scotti ${ }^{1}$ \\ 1 Universidade Federal de Uberlândia - UFU, Grupo Centro de Pesquisa e Desenvolvimento de Processos de Soldagem, \\ Uberlândia, MG, Brasil.
}

Recebido: 29 Ago., 2017

Aceito: 16 Out., 2017

E-mail: ascotti@ufu.br(AS)
Resumo: Aulas práticas são de fundamental importância em cursos de engenharia, para que os estudantes se sintam expostos a uma atmosfera real da aplicação dos conhecimentos teóricos. O presente trabalho tem o objetivo de demonstrar como o apoio audiovisual às aulas práticas pode melhorar a eficácia das mesmas, tanto por facilitar os docentes como por fomentar o alcance do aprendizado por parte dos estudantes. Implantado pelo autor em disciplinas de soldagem no curso de engenharia mecânica da UFU em nível de pós-graduação, a iniciativa visou tornar as aulas menos trabalhosas para os instrutores, pelo melhor aproveitamento de tempo e recursos laboratoriais, sem tirar a atratividade para os alunos. Sempre procurando garantir a participação ativa dos estudantes durante as práticas, para não se tornarem apenas espectadores durante a execução dos experimentos, os alunos são encorajados inicialmente a conhecer e praticar atividades nos laboratórios. Em seguida, se emprega o artifício do apoio audiovisual somente em substituição a atividades repetitivas e passivas. São apresentados 2 exemplos de aplicação, com ênfase na formação (verificação de fenômenos físicos e conceitos teóricos) e informação (apresentação de técnicas e procedimentos laboratoriais). Conclui-se que os objetivos desta abordagem foram alcançados, mas que a avalição do efeito sobre o aprendizado só será possível ao longo dos anos de aplicação do método.

Palavras-chave: Aulas práticas; Aulas assistida por audiovisual; Aprendizado.

\section{Increasing of Welding Learning Effectiveness by Laboratory Classes Assisted with Non-passive Audio-visual}

\begin{abstract}
Lab classes are of essential importance for engineering courses, for exposing students to an actual atmosphere during application of the theoretical knowledges. This work has the objective of demonstrating how audiovisual assisted lab classes can improve the effectiveness of the classes, as much for supporting the tutor as for boosting the students' learning. Implemented by the author in post-graduate courses of Mechanical Engineering at Federal University of Uberlandia, Brazil, the aim was to turn classes less laborious for the teachers and concomitantly more attractive and efficient to the students, while time and lab resources are more effectively used. Always trying to assure active participation of the students (not as passive spectators) during the execution of the experiments, the students are at first encouraged to get acquainted to laboratorial practices. Following, audiovisual resources are used complementary to replace only the repetitive and/or passive activities. The methodology applications were over disciplinary topics, with emphasis on the formative (certification of physics phenomena and theoretical concepts) and information (presentation of techniques and processes) aspects. It was concluded that the objectives of this approach have been achieved, but the assessment of the effect on learning will be possible over the years of method implementation.
\end{abstract}

Key-words: Lab classes; Audiovisual assisted classes; Learning.

\section{Introdução}

Aulas práticas são de fundamental importância em cursos de engenharia, por deixarem estudantes expostos a uma atmosfera real da aplicação dos conhecimentos, fato não possível de se alcançar em plenitude somente em aulas teóricas expositivas. A tecnologia da soldagem, quando ensinada através dos seus fundamentos (como em nível de pós-graduação), torna-se uma disciplina na qual se aplica conhecimentos interdisciplinares, passando por eletricidade, condução de calor, física do plasma, metalurgia, etc.. Sendo assim, quando não ensinado apenas como conteúdo informativo, a tecnologia
Este é um artigo publicado em acesso aberto (Open Access)
sob a licença Creative Commons Attribution Non-Commercis que permite uso, distribuição e reprodução em qualquer meio, sem restriçōes desde que sem fins comerciais eque 0 trabalho original seja corretamente citado. 
Aumento da Eficácia do Aprendizado de Soldagem por Aulas Práticas Assistidas por Audiovisual de Forma Não Passiva

da soldagem pode se tornar um tópico de difícil assimilação, onde os alunos são exigidos a visualizar as relações entre várias variáveis e áreas de conhecimento para entender e/ou explicar os fenômenos que ocorrem. Torna-se, então, de grande valia e importância a exibição prática dos fenômenos que ocorrem em processos de soldagem, como forma de agregar e consolidar os conhecimentos teóricos. Textos didáticos, mesmo em português, sobre os fenômenos que ocorrem, como a característica do arco, características das fontes de alimentação e o efeito dos agentes de controle no processo de soldagem, podem ser encontrados em inúmeras fontes (por exemplo, Wainer et al., 1992; Quites, 2002; Marques et al., 2005; Scotti e Ponomarev, 2014). Entretanto, a confirmação prática desses fenômenos é mais trabalhosa, porém exequível.

Por exemplo, existem equipamentos de soldagem com fontes convencionais e fontes eletrônicas, sendo estas últimas amplamente utilizadas pela tecnologia de soldagem atual, pois oferecem recursos operacionais e segurança elevada aos operadores. No entanto, existem modos básicos de operação por traz de qualquer que seja a fonte, como as chamadas Características Estáticas das Fontes (CEF). Caso o usuário não tenha uma visualização individual do efeito da CEF sobre os sinais elétricos durante o processo de soldagem, ele terá dificuldades em entender razões para que equipamentos com fontes eletrônicas funcionem de forma diferenciada, já que podem operar como uma fonte de tensão constante ou uma fonte de corrente constante. O meio mais fácil de mostrar estas particularidades é através de ensaios de simulação experimental, com aplicação de carga resistiva às fontes, e assim construir as curvas de CEF sob condições variadas. Sabe-se também que existem modos intrínsecos (Controle Interno ou Externo) para se controlar o comprimento do arco no processo MIG/MAG, que são executados pelas próprias fontes sem interferência do operador, auxiliando a estabilização do arco de soldagem. Este mecanismo de controle pode ser comprovado executando-se uma soldagem MIG/MAG com variação de parâmetros e condições de soldagem, impondo uma inclinação na superfície da chapa a ser soldada e, assim, verificar, por exemplo, a autorregularem do comprimento do arco, tanto para o modo tensão ou corrente constantes.

Em exposição somente teórica, torna-se trabalhoso repassar aos estudantes de forma clara os conceitos sem a visualização dos fenômenos envolvidos. Pode-se, então, e deve-se, demonstrar os fenômenos relacionados com a tecnologia através de experimentos práticos em laboratório, utilizando-se para cada caso equipamentos específicos. Entretanto, apesar das tentativas de se introduzir melhores aulas práticas em disciplinas de soldagem em várias instituições, inúmeras limitações têm sido apontadas, dentre elas se destacam: a) demanda por grande número de equipamentos e sistemas de monitoramento; b) insuficiência de espaço físico dedicado a aulas práticas; c) experimentos demorados (preparação e execução), limitando o número de experimentos por aula; d) alto custo do material de consumo; e) baixa disponibilidade de carga horária por parte dos alunos; f) excessivo número de alunos por classe, fazendo com que nem sempre todos realmente participem ativamente dos experimentos; g) inexistência de equipamentos didáticos comerciais nesta área, como os módulos para física; h) por último, mas não menos importante, existem sempre chances de um fato fora de controle levar o experimento a dar resultados não esperados, prejudicando, ao invés de melhorando, o aprendizado.

Em busca da superação destas dificuldades que se tornam necessários métodos mesmo que nem tão inovadores, mas criativos, que possam, se não suprimir totalmente estas dificuldades, pelo menos contorná-las, de modo a aumentar a eficiência do ensino da tecnologia da soldagem através de aulas práticas. Neste contexto, foi proposto um projeto com o objetivo de elaborar uma metodologia didática que permita passar de forma experimental uma maior quantidade de tópicos aos alunos, sem acréscimo de carga horária, mas otimizando tempo e recursos. A proposta é também de garantir aos alunos uma ação ativa durante a execução dos experimentos (não ficar passivamente observando sua realização), para evitar que as soluções de alguns problemas impactem na criação de outros problemas de cunho didático.

\section{Metodologia e Procedimento de Trabalho}

A proposta deste trabalho é elaborar e operacionalizar aulas práticas de soldagem em laboratórios que: a) sejam atrativas, através do sentimento de realidade (ambiente laboratorial) e transferência de conhecimento; b) demandem menos tempo de preparação e execução por parte do docente, para que o mesmo se dedique mais à discussão do assunto com os alunos; c) sejam de baixo custo (serviço de usinagem, por exemplo, e material de consumo); d) sejam livres de fatos fora de controle para evitar resultados contraditórios; e) garantam participação total e individual dos estudantes; f) otimize o tempo do estudante; e g) uma maior número de experimentos possa ser demonstrado por aula. Para atingir estas características, a provável originalidade desta proposta de ensino está 
na forma de otimização dos recursos, ao se propor usar recursos audiovisuais apenas para substituir as atividades repetitivas e/ou passivas. Para melhor explicar esta metodologia, considera-se como exemplo um experimento de laboratório para demonstrar aos alunos a influência da energia do arco na penetração do cordão.

$\mathrm{Na}$ abordagem convencional: a) as placas de teste devem ser encomendadas e preparadas antecipadamente (uso intensivo de oficina); b) os equipamentos do laboratório de soldagem (soldagem e monitoramento) devem ser configurados; c) os alunos obsevam a realização de todas as soldas (digamos, 3 experimentos) a serem realizadas. Eles devem, ao mesmo tempo, ler e anotar os parâmetros de soldagem para fins de relatório (às vezes, se revezando). Deve-se destacar que há "tempo morto" entre o fim de uma solda e a preparação para a próxima; d) a placa de teste deve ser levada a um laboratório metalográfico, para ser cortada, lixada, polida e atacada; e) as amostras seriam então levadas para um microscópio tipo estereoscópio para ter as dimensões da seção transversal medidas. Como se vê, a abordagem de aula prática convencional pode-se tornar extremamente longa (especialmente para preparar micrografias) e cara (despesas de consumíveis e uso de pelo menos quatro laboratórios). E para repeti-la para outro grupo, todos os procedimentos devem ser replicados. Não é de se admirar que um experimento muito instrutivo como esse dificilmente seja proposto em aulas práticas nos cursos de soldagem.

$\mathrm{Na}$ abordagem proposta, todo o protocolo acima seria realizado apenas uma vez. Um breve vídeo seria preparado para mostrar todos os experimentos, de tal forma que todos os valores de regulagem dos parâmetros e monitoração seriam mostrados de forma amigável e detalhada. Os alunos receberiam antecipadamente um guia com os objetivos, dados, configuração e descrições experimentais, macrografias/oscilogramas finais identificados por experimentos e tabelas padrões para anotar os resultados. A aula de laboratório propriamente dita começa com a demonstração real do experimento no laboratório, mas sem executar todos os experimentos (como os alunos não precisam prestar muita atenção, nem nas informações de configuração, nem no monitoramento de parâmetros, eles podem se concentrar no processo em si e na soldagem). Esta abordagem evita repetir o experimento de forma exaustiva no laboratório para se verificar a relação causa e efeito da alteração de parâmetros (a parte mais demorada e dispendiosa).

Como demonstração leva muito menos tempo do que executar experimentos pela abordagem convencional (com ênfase no fato de que menos rigor na parametrização experimental é tomada pelo tutor nas demonstrações), há tempo sobrando para executar outras demonstrações relacionadas a diferentes experimentos. Após as demonstrações, os alunos vão a uma sala de aula, onde os vídeos são apresentados a eles sob a supervisão do tutor (que pode esclarecer dúvidas). Nos vídeos, os alunos poderão, de forma individualizada (forçando a participação) ver, e rever se necessário, os ensaios, mas principalmente coletando os dados experimentais de forma concomitante, como se estivessem no próprio laboratório assistindo em tempo real os experimentos. Eles finalmente preparam o relatório para ser entregue ao tutor. Planilhas são fornecidas aos alunos para que possam ser preenchidas e usadas como base para elaboração do relatório final, com as observações realizadas do experimento.

Assim, os alunos (individualmente ou em grupos) observam os acontecimentos e fazem anotações o tempo todo, garantindo a não passividade dos mesmos, fato que nem sempre é observado em videoaulas didáticas ou em muitas metodologias de ensino a distância. Com o apoio dos recursos áudios-visuais, a qualidade do experimento poderá ainda ser intensificada, buscando-se fazer os experimentos de forma clara e ordenada, mostrando os passos de execução, garantindo uma melhor observação dos fenômenos. Com o uso da técnica de edição, podem-se adicionar imagens em câmera lenta, permitindo a visualização de fenômenos impossíveis de serem observados a olho nu, devido a suas velocidades de acontecimento e baixo nível de segurança (que estariam sujeitos os estudantes ao tentarem observar tais fenômenos, como ficando expostos aos agentes nocivos).

Para demonstrar a eficácia do método, planejou-se atividades experimentais que pudessem cobrir de forma mais abrangente os conceitos apresentados em aulas teóricas da dada disciplina, tornando o aprendizado da teoria completo, com seus aspectos teóricos e práticos dos fenômenos estudados. Após esta etapa, formas de se utilizar recursos audiovisuais em cada uma das atividades experimentais foram verificadas, elaborando-se um roteiro para realização dos experimentos (fases teórica e experimental). Os experimentos foram, então, executados e a mídia desenvolvida (mesmo que de forma amadora, através de filmadora e placa de aquisição e programa de edição de imagens não profissionais). Foi elaborado para cada experimento um "Manual do Professor", contendo todos os procedimentos a serem executados, a relação de insumos e equipamentos, "kits" de corpos de prova a serem utilizados, dados, amostras, filmes, resultados esperados de cada experimento, etc., e um "Guia para o Aluno", enfatizando as aplicações e objetivos do experimento, bem como os fundamentos dos fenômenos 
apresentados, funcionamento dos equipamentos, tipo e forma dos sinais monitorados, dados suplementares para elaboração de planilhas e roteiro para avaliação (relatório e/ou exercícios), com o intuito de não apenas agregar os conhecimentos vistos mas também forçar os estudantes a se envolver e procurar entender os acontecimentos, não apenas observá-los.

\section{Aplicação da Metodologia}

A título de exemplo, são apresentadas as sequências de dois experimentos, como a seguir. Mas diversos outros experimentos já foram elaborados, tais como: 1) Determinação da eficiência de fusão (TIG em aço ao carbono e aços inoxidáveis); 2) Abertura de Arco (contato e pulso com alta tensão); 3) Fenômeno da limpeza catódica em soldagem de alumínio × aço inoxidável; 4) Determinação das características estáticas de arcos (eletrodos consumíveis e não consumíveis); 5) Determinação das constantes da equação de taxa de fusão para diferente gases de proteção e material do eletrodo; 6) Determinação do efeito da conexão de cabo, direção de tocha e comprimento do arco sobre sopro magnético; 7) Determinação da corrente de transição globular para goticular para diferentes gases de proteção; 8) Determinação da transição das transferências curto-circuito para globular diferentes gases de proteção; 9) Efeito da variação da inclinação da tocha (puxando ou empurrando) sobre a geometria do cordão; 10) Efeito da regulagem da tensão e indutância sobre a regularidade da transferência metálica em curto-circuito; 11) efeito da regulagem da tensão sobre a geometria do cordão e consumo de fluxo em arco submerso

\subsection{Levantamento das características estáticas de uma fonte eletrônica}

Neste experimento, procura-se demonstrar o comportamento de uma fonte eletrônica para soldagem a arco elétrico, nos modos operacionais Tensão Constante e Corrente Constante, quando submetidas a uma carga resistiva. Durante a aula de laboratório, depois uma explicação do experimento (fenômenos a serem observados, equipamentos e insumos a serem utilizados), é relembrado aos alunos que no modo corrente constante é permitida a regulagem da corrente de trabalho e, de acordo com a sua curva estática tensão-corrente, é produzida uma corrente de trabalho relativamente constante dentro da faixa de trabalho. No roteiro é ainda explicado que a tensão, para uma dada corrente, retrata a velocidade na qual o eletrodo consumível é alimentado no arco, exceto quando o eletrodo não consumível é usado, para o qual a tensão retrata a distância eletrodo-chapa. Já no modo tensão constante, ocorre apenas a regulagem da tensão de trabalho (correspondente a uma curva estática tensão-corrente), tendendo a produzir uma tensão de trabalho relativamente constante. A corrente, para uma dada tensão, retrata a velocidade na qual o eletrodo consumível é alimentado no arco. É também demonstrado que qualquer carga resistiva simula o arco em termos de levantamento da CEF (mas não em termos do arco em si).

A demonstração do experimento em si é para mostrar a todos os alunos como se determina a Característica Estática da Fonte (CEF) de uma dada fonte de soldagem. Isto é possível ao se usar uma bancada de carga resistiva, variando-se a resistência e medindo-se a tensão e corrente sob diversas regulagens do equipamento, em qualquer que seja seu modo operacional. A Figura 1 ilustra a montagem dos componentes para a realização do experimento

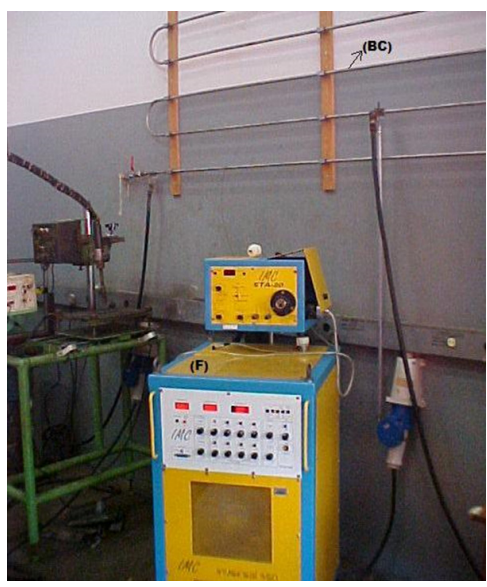

Figura 1. Vista geral dos equipamentos utilizados no experimento para determinação de CEF de uma fonte eletrônica, onde (F) é a fonte, (BC) é o banco de carga resistiva. 
no laboratório. Ao longo do experimento, aproveita-se para mostrar aos alunos as diferenças entre uma fonte convencional e uma fonte eletrônica, assim, aumentando o alcance didático, além dos objetivos já estipulados na aula prática.

Deve-se destacar que os ajustes das regulagens da fonte e da carga e trocas de fontes demandam muito tempo (tempo "morto" do ponto de vista de aprendizagem). Além disto, muitos alunos ficam passivamente participando, pois normalmente o instrutor é quem muda as regulagens ou troca as fontes, por demandar conhecimentos práticos. Se precisa apenas de um aluno para ler os valores de corrente e tensão a cada regulagem. Assim, muitas vezes os alunos ficam desmotivados com o experimento.

Após a demonstração, todos os experimentos com diversas variáveis são visualizados pelos alunos em uma sala com projeção de vídeo. A Figura 2 ilustra telas de apresentação de um dos vídeos. Ou seja, o vídeo

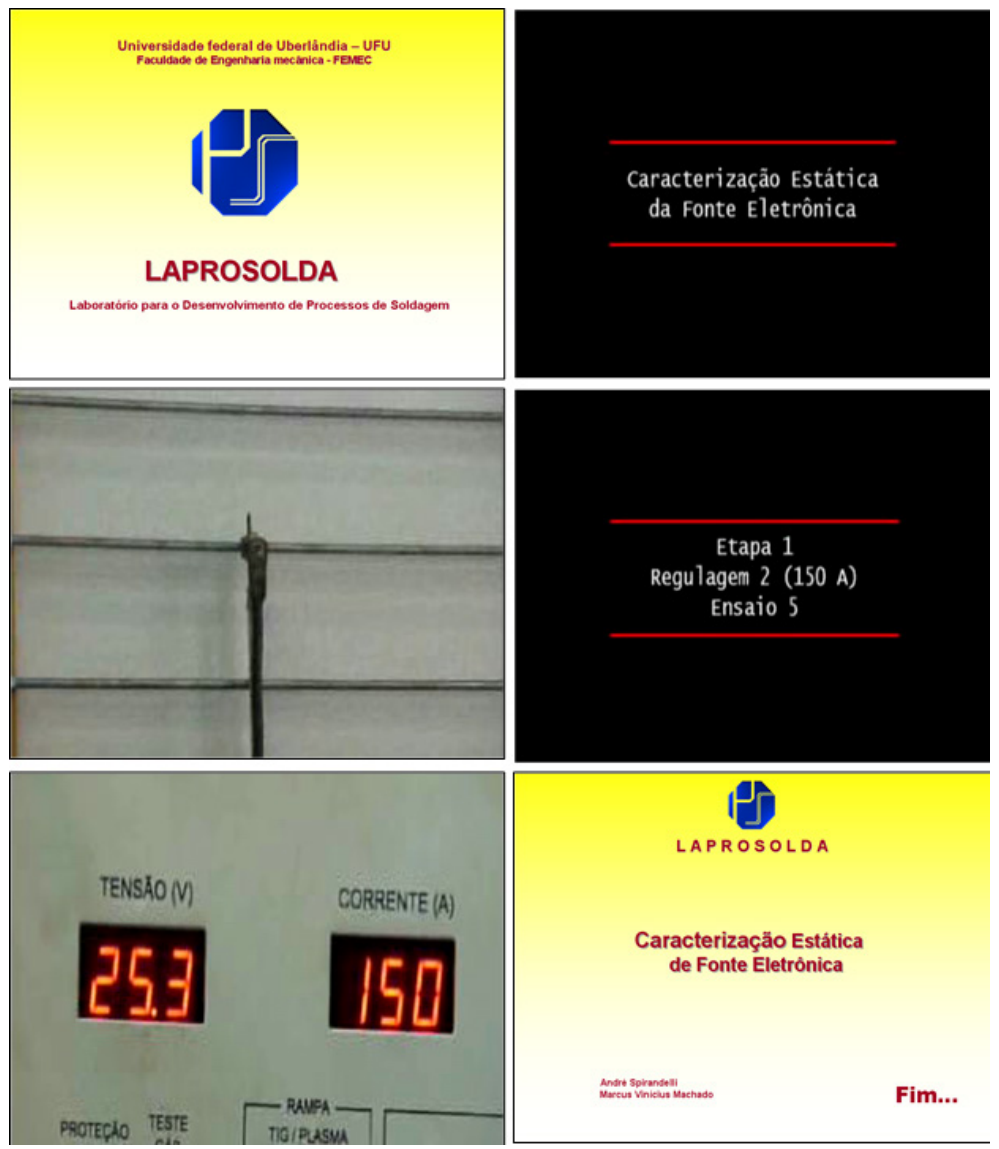

Figura 2. Telas ilustrando diferentes fases do vídeo sobre o levantamento de Características Estáticas de Fontes.

mostra a aula prática elaborada para se originar as Características Estáticas de Fontes (resposta da fonte quanto ao comportamento não transiente da corrente e da tensão em relação ao tempo) sob diferentes regulagens, ou seja, medições da CEF para regulagens diferentes de corrente, com a fonte trabalhando em modo operacional de corrente constante ou com a fonte trabalhando em modo operacional de tensão constante. Nos vídeos, é mostrado o mostrador digital de leitura dos parâmetros elétricos durante os ensaios, o qual é ilustrado pela Figura 3 . Tabelas padrão são distribuídas antecipadamente a todos os alunos, que anotam os valores de corrente e tensão de cada ensaio durante a apresentação do vídeo.

É proposto ao aluno para confecção do relatório fazer uma introdução, contendo informações da literatura básica a definição de CEF e sobre a diferença entre fontes do tipo corrente constante e tensão constante. Mas eles devem compulsoriamente apresentar os resultados dos experimentos mostrados em vídeo e compilados em tabelas, possibilitando-os a levantar gráficos de I (Corrente) $\times$ U (Tensão) (Figura 4) para cada modo operacional da fonte. 


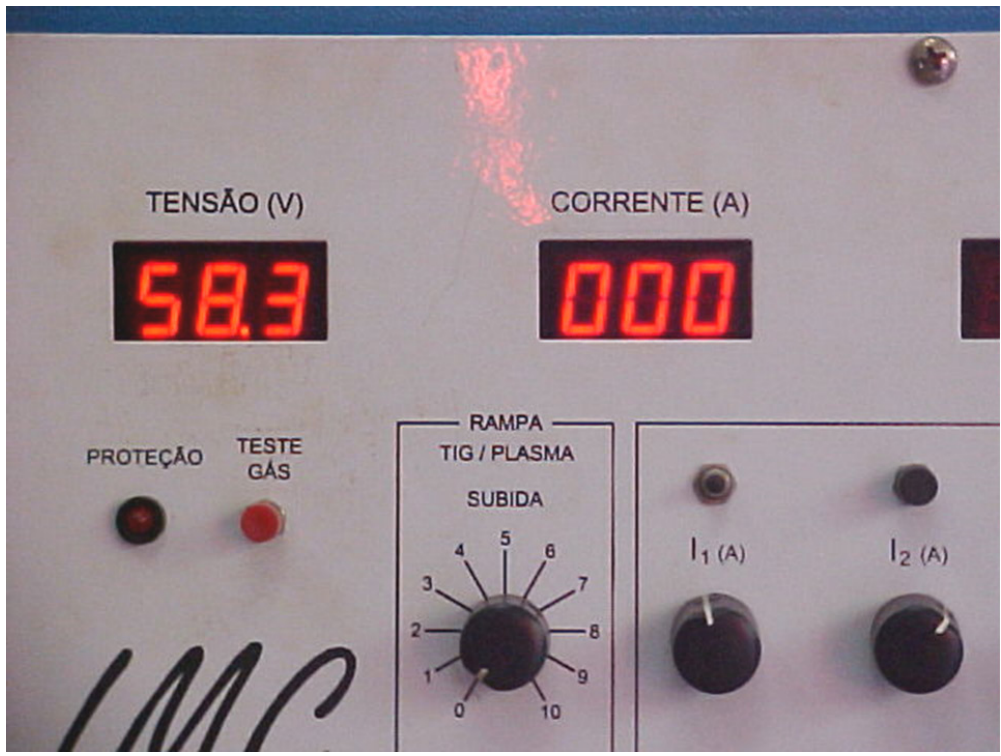

Figura 3. Painel da fonte - exemplo do caso da medida da tensão em vazio (fonte sem carga).

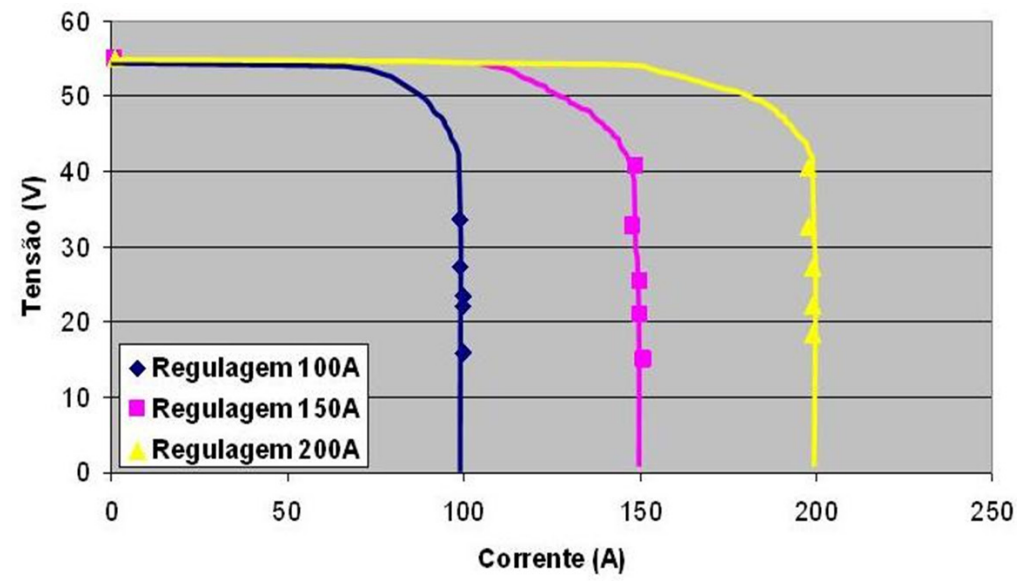

Figura 4. Exemplo de gráfico da fonte trabalhando no modo corrente constante, obtido no levantamento da CEF.

\subsection{Controle do comprimento do arco}

Em soldagem, um dos parâmetros mais importantes de ser mantido constante é o comprimento do arco elétrico. Objetiva se em experimentos demonstrar a influência do tipo de fonte de alimentação e modo de operação sobre o controle automático do comprimento do arco em uma soldagem MIG/MAG.

Os alunos inicialmente visitam o laboratório e recebem como introdução uma revisão teórica da importância do controle do comprimento do arco e seus métodos de controle, apontando as dificuldades práticas e vantagens sobre o processo de soldagem. É em seguida mostrada a montagem necessária para realização do experimento, indicando os equipamentos tais como fontes, tochas, gases, arames de solda, sensores de monitoração e aquisição de dados, e explicando a função e importância de cada instrumento sobre o processo prático. Como em todas as práticas realizadas no projeto, é uma oportunidade para os alunos presenciarem o processo, neste caso em especial quanto às diferentes regulagens de parâmetros e suas influências sobre o processo. É, então, realizado um ensaio demonstrativo do referido controle e suas características.

Os alunos são, então, levados à sala multimídia, onde são passados os vídeos com o conjunto de experimentos, com ênfase nas alterações que ocorrem frente às atuações do controle da fonte, dependendo do modo operacional 
(diferentes CEF e com controle habilitado e desabilitado). Ainda durante o filme, o professor pode, achando necessário, congelar a imagem para complementar com informações aos alunos. Os alunos assistindo aos vídeos devem anotar em suas planilhas do Guia do Aluno dados dos experimentos, tais como tensão, corrente, velocidade de alimentação do arame e imagens do comprimento do arco, que são mostrados de modo sincronizados entre si durante o processo.

Os ensaios realizados para demonstrar os fenômenos, tanto com a fonte no modo tensão constante quanto em corrente constante, são embasados em se alterar continuamente a DBCP (Distância do Bico de Contato a Peça), conforme Figura 5. Varia-se o sentido de soldagem a fim de se observar a aplicabilidade do processo em diferentes condições, com a DBCP aumentando ou diminuindo. A região do arco é filmada com filtros tipo máscara de solda convencional, que proporcionam aos alunos a sensação real de estarem no laboratório observando o acontecimento dos fenômenos. O filme mostra que o comprimento do arco se mantém praticamente inalterado ao longo do processo mesmo sob nítida variação da DBCP. Além de filmadas, as soldagens são monitoradas em relação aos parâmetros de tensão, corrente e velocidade de alimentação, por instrumentos próprios do laboratório via computador.

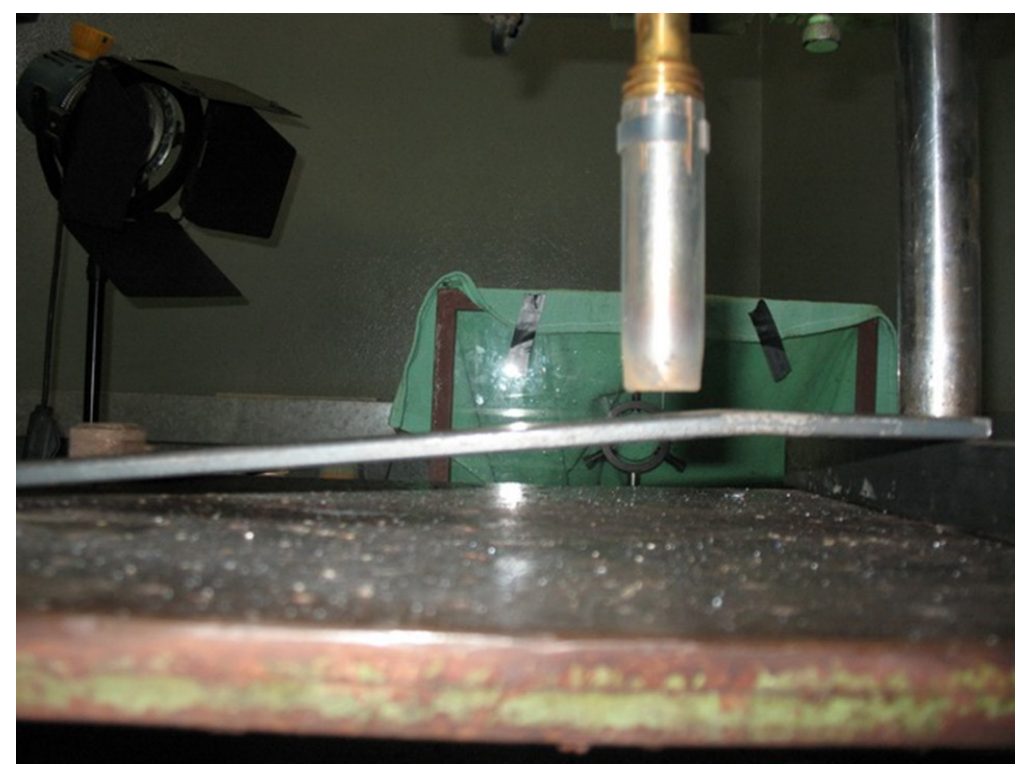

Figura 5. Detalhe da inclinação da chapa para os ensaios realizados.

Para se demonstrar a ação do controle interno (fonte operando no modo tensão constante), é exibido a todos os alunos um vídeo mostrando o arco deslocando-se sobre a chapa inclinada, exibindo-se antes os parâmetros regulados, sendo no caso específico a DBCP, a tensão e a velocidade de alimentação. Como a projeção do vídeo é amplificada, os alunos podem visualmente avaliar se há variação ou não do comprimento do arco ao longo do percurso do arco. Logo após anotarem suas observações, os alunos podem trabalhar sobre o guia do aluno, no qual são exibidos oscilogramas de tensão, corrente e velocidade de alimentação, sincronizados com imagens do comprimento do arco ao longo do tempo (Figura 6). Desta forma, os alunos podem correlacionar e teoricamente justificar potenciais variações da tensão, corrente e velocidade de soldagem frente ao comportamento do comprimento do arco. No caso da Figura 6, o comprimento do arco não se altera, a velocidade de alimentação ficou constante e a tensão e corrente caíram um pouco. A pequena queda da tensão e corrente são justificáveis, pela não planicidade da CEF e pelo aumento do comprimento do eletrodo livre, respectivamente (e os alunos devem ficar conscientes disto).

A verificação do controle externo tem particularidades se comparada à anterior, pois envolve variação da velocidade de alimentação, pois é sobre esta que se dá a ação clássica do controle. Além disto, no modo operacional corrente constante, pode-se ativar ou não a função de controle de arco, permitindo a comparação de duas situações (no modo de tensão constante, necessário para verificar o controle interno, isso não é possível, 


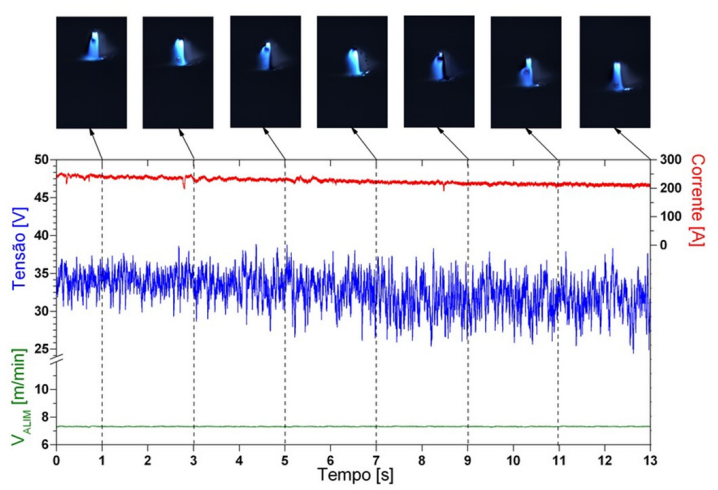

Figura 6. Visualização da ação do controle interno, através da sincronização do arco ao longo de uma soldagem sobre uma placa inclinada (Figura 5) com os parâmetros do processo (corrente, tensão e velocidade de alimentação).

já que existe o fenômeno de auto-ajuste do comprimento do arco). Para ambas situações, o vídeo inicialmente mostra a regulagem no equipamento da corrente e velocidade de alimentação e do posicionamento da tocha em relação à chapa de teste. Com a função ativada, regula-se ainda a tensão de arco. Em seguida o vídeo mostra o arco deslocando-se sobre a chapa inclinada. Na função desativado, o tamanho do arco de soldagem naturalmente não se mantém com o avanço deste. Assim, os vídeos oferecem a oportunidade de se observar de forma mais clara tanto a mudança do tamanho do arco, função desativada, quanto a permanência do arco no mesmo comprimento, com a função ativada. De forma análoga, os alunos podem trabalhar sobre o guia do aluno, no qual são exibidos os oscilogramas de tensão, corrente e velocidade de alimentação, sincronizados com imagens do comprimento do arco ao longo do tempo, para as duas situações (Figura 7). Observa-se a variação do comprimento do arco com a função de controle externo desativada, já que não há variação da velocidade de alimentação.

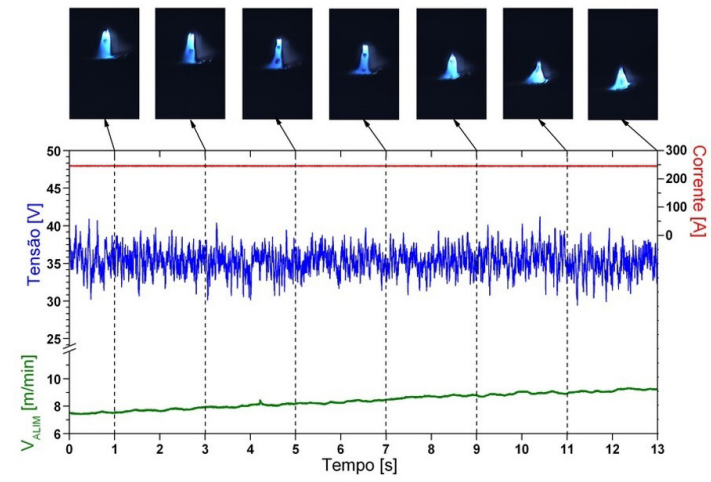

(a)

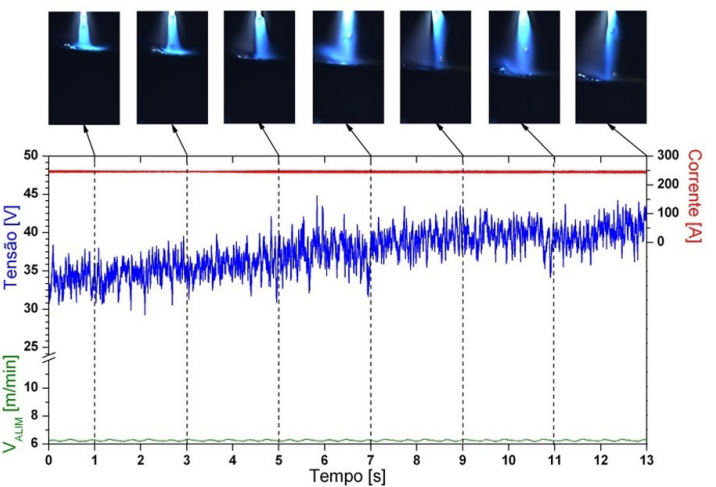

(b)

Figura 7. Visualização da ação do controle externo, através da sincronização do arco ao longo de uma soldagem sobre uma placa inclinada (Figura 5) com os parâmetros do processo (corrente, tensão e velocidade de alimentação), sendo em (a) com o controle ativado e em (b) com o controle desativado. 
Finalmente, na elaboração do relatório, os alunos além de introduzirem os conceitos dos modos de controle, tomando como fonte a literatura indicada, estarão com fotos dos processos onde poderão mensurar o comprimento do arco, indicando o possível modo de operação do experimento e relacioná-lo aos resultados vistos em vídeo e com todos os parâmetros referentes ao processo.

\section{Avaliação Geral}

Deve se destacar uma importante diferença entre a presente proposta para a de vídeos de assuntos tecnológicos usados em tele-educação (por exemplo, telecursos) ou cursos à distância, onde as abordagens são totalmente não presencias, portanto passivas. Outro ponto de análise e objetivo da proposta está na relação tempo benefício, sendo o tempo um dos fatores mais limitadores quanto ao quesito de repassar informações aos estudantes. Assim, o tempo de duração de cada filme foi projetado para ficar entre 5 a 6 minutos para cada prática, sendo então possível executar a exibição de cada prática em torno de 25 minutos, incluindo a parte no laboratório. Desta forma, é possível em uma aula normal ( 2 horas-aula de 50 minutos cada) se conduzir até 4 experimentos. Fazer as mesmas práticas de forma convencional, realizadas somente em laboratório, levaria no mínimo o dobro do tempo gasto, além de, não menos importante, haver a possibilidade de, por motivos aleatórios e inesperados, os experimentos não funcionarem de acordo com o desejado. Este fato comumente vivenciado em ambientes de laboratório, pode deixar os estudantes desestimulados ou com dúvidas e incertezas quanto a veracidade dos fenômenos, dificultando a confecção dos relatórios finais. Reafirma-se também a economia de insumos para realização de práticas.

Pensa-se em disponibilizar parte dos vídeos para os alunos, de forma que venham fazer a etapa de anotações em horários convenientes, sem a presença do instrutor, podendo assim ficar concentrado nas informações passadas pelo instrutor em sala. É sabido que se podem utilizar técnicas pedagógicas para identificar grupos de alunos com maior facilidade nesta abordagem de aprendizado, diferentemente dos alunos que precisam de uma forma presencial mais intensiva para melhor aproveitamento e aprendizado. Por outro lado, aumenta-se o número de tarefas extraclasse para os alunos, sendo conflitante com a necessidade de ser a baixa carga horária livre dos alunos e docentes. Todos estes pontos direcionam para a necessidade de fazer uma avaliação mais completa e sistemática da metodologia proposta, com a ajuda de profissionais da área de educação.

\section{Conclusões}

Pela aplicação até o momento desta metodologia, ela confirma ser útil na redução de recursos laboratoriais e apresenta um ganho no número de atividades expostas aos alunos, uma vez que se economiza em tempo para execução de cada atividade (tempo morto de regulagem dos equipamentos para variações de parâmetros é suplantado). Assim os alunos estão sendo formados com uma carga horária mais efetiva e intensa e com uma abordagem maior de conhecimento, levando-se a uma formação mais completa e aproveitadora. Por outro lado, os resultados da eficácia didática desta abordagem não foram ainda avaliados de maneira criteriosa do ponto de vista pedagógico.

\section{Agradecimentos}

Ao LAPROSOLDA/UFU pela disponibilização e investimento em infraestrutura e custeio dos insumos para realização do projeto e em particular aos acadêmicos Marcus V. R. Machado, Diandro B. Fernandes e André S. R. Costa, pela realização dos experimentos. Os autores também agradecem aos órgãos de fomento FAPEMIG (programa PIBIC) e CNPq (programas PIBIC, DTI e PQ) pelas bolsas para desenvolverem trabalhos de pesquisa.

\section{Referências}

Marques PV, Modenesi PJ, Bracarense AQ. Soldagem: fundamentos e tecnologia. Belo Horizonte: Editora UFMG; 2005. 363 p.

Quites AM. Introdução à soldagem a arco voltaico. Florianópolis: Ed. Soldasoft; 2002.
Scotti A, Ponomarev V. Soldagem MIG/MAG: melhor entendimento, melhor desempenho. 2. ed. São Paulo: Artliber Editora; 2014. 288 p.

Wainer E, Brandi SD, Melo FDH. Soldagem: processos e metalurgia. São Paulo: Edgard Blücher Ltda; 1992. 